


\section{Um Ventoforte soprou sobre a infância: teatro com crianças da comunidade Associação Esperança de Santa Maria/RS}

Ana Paula Gomes Marques

Recebido em: 15/05/2019

Aprovado em: 10/06/2019

DOI: $10.5965 / 2358092521212019117$ 


\section{RESUMO}

O presente artigo compartilha com o leitor algumas reflexões que emergiram de minha pesquisa de Trabalho de Conclusão de Curso em Licenciatura em Teatro, pela Universidade Federal de Santa Maria (UFSM). Com o objetivo de investigar as relações entre teatro, infâncias e comunidades, a pesquisa se desenvolveu tendo as crianças da Associação Esperança (Camobi, Santa Maria/RS) como parceiras de trabalho e sujeitos da investigação. A questão da pesquisa se delineou a partir da interrogação: o que as crianças criam a partir da linguagem teatral? Nos encontros que se realizaram semanalmente, foram experimentadas as práticas de Ilo Krugli e do Teatro Ventoforte, que possibilitaram que as crianças, que não haviam tido contato anteriormente com a linguagem teatral, pudessem criar e se expressar por meio dessa arte.

Palavras-chave: teatro com crianças; teatro Ventoforte; teatro na comunidade.

\section{CONSIDERAÇÕES INICIAIS}

Pensar sobre a infância me leva a um tempo passado, a uma idade que era boa para se imaginar, brincar, sonhar e viver. Lembro-me de minha infância com saudades, das brincadeiras com os "primos", com a galera do bairro, na grama, na lama, na chuva. Das bonecas, das casinhas, dos vampiros e heróis que habitavam nossas histórias de criança. Falar de infância me leva a resgatar o momento em que meu ser criança olhava o mundo em volta com olhos grandes e cheios de sonhos.

A curiosidade pelo ser criança me levou por diversos caminhos e um deles, felizmente, levou-me ao Grupo de Estudos sobre Teatro e Infâncias (GETIs/CNPq). Desde o início, instigou-me 
o "s" que completava a palavra infância. Durante nossos encontros teóricos e práticos, foi se revelando a significância daquele "s" e reafirmei meu pensamento sobre a pluralidade da infância.

Nos encontros do GETIs, criamos um espaço onde as noções de infâncias delineavam todas as discussões teóricas e experimentações práticas/teatrais. E foi nesse espaço que me questionei sobre o teatro feito para e com as crianças. Anteriormente, pensava naquele "teatrinho" para "criancinhas", que costuma ser colorido e barulhento, além, claro, de ter princesas indefesas, príncipes valentes, bruxas malvadas e "por aí vai". Essa experiência me fez pensar sobre novas possibilidades de fazer teatro com as crianças, indo além dos contos de fadas e histórias clássicas, prioritariamente "ofertadas" para elas.

O querer estar junto das crianças me levou para além de um espetáculo, de uma escola, ou do meio acadêmico. Meus devaneios de estudante-artista-professora me levaram a conhecer algumas comunidades na cidade de Santa Maria/RS, despertando um desejo de ir além dos muros da universidade. Acredito ser mais que um desejo; uma necessidade. Encontrei na comunidade um espaço de diálogo aberto com as crianças e demais membros. Penso que não podemos nos limitar a uma sala de ensaio, fechada e afastada do "mundo real" e das "pessoas reais".

Todas estas questões delinearam minha pesquisa de conclusão de curso em Licenciatura em Teatro, no ano de 2018. Nessa investigação, busquei por uma abordagem metodológica que recuperasse a presença das crianças enquanto parceiras e criadoras, e não apenas ouvintes. Foi então, que mais um encontro feliz aconteceu: meu encontro com o Teatro Ventoforte. Logo de início percebi que algumas práticas desenvolvidas por esse grupo tinham por objetivo desvendar o ser criança, sua infância, seus caminhos e suas histórias. Pensei: "é esse teatro que me interessa".

Dessa maneira, o tema de minha pesquisa surgiu a partir do entrelaçamento de três temas: teatro, infâncias e comunidade, configurando-se da seguinte maneira: uma investigação das criações das crianças a partir das práticas artístico-pedagógicas do Teatro Ventoforte, com crianças da comunidade Associação Esperança de Santa Maria/RS. 
A problemática da pesquisa emergiu a partir da seguinte interrogação: o que criam as crianças? Essa pergunta inicial, foi de importância imensurável para delinear os objetivos da pesquisa, uma vez que, não se tratava de uma análise psicológica em relação às criações das crianças, muito menos interpretativa. $O$ objetivo da pesquisa se delineou a partir da proposição de experimentações teatrais a partir das práticas do Teatro Ventoforte, possibilitando a investigação das criações das crianças de uma comunidade. Se tratava de um desejo de organizar uma maneira de expor seus desenhos, seus caminhos, seus contextos de vida, suas histórias, de maneira que suas vozes pudessem ser ouvidas em suas criações a partir da linguagem teatral.

Em conformidade com o que foi exposto, para abordar as relações entre Teatro e Comunidade a principal referência é a pesquisadora brasileira Marcia Pompeo Nogueira (2015, 2009, 2008). Os sociólogos da infância Manuel Jacinto Sarmento (2011, 2008, 2005), Claude Javeau (2005) e Régine Sirota (2001) são as referências para dialogar com a Sociologia da Infância. A partir das pesquisas de Marcia Pompeo Nogueira $(2015,2008)$, Miguel Vellinho Vieira (2008) e leda de Abreu (2009), aproximei-me do trabalho de Ilo Krugli no Teatro Ventoforte. Os autores compartilham considerações importantíssimas, no âmbito teórico-prático, acerca do que propõe esse teatro e qual sua relação com as crianças.

\section{SOBRE PENSAR AS CRIANÇAS E SUAS INFÂNCIAS}

Ao longo da história da humanidade, como nos aponta Neil Postman (1999), a criança ocupou diferentes espaços na organização das sociedades: no Período Clássico - povos gregos e romanos - pouca atenção se direcionava à infância, não havendo um conceito para designar essa geração ou mesmo uma diferenciação nas etapas do desenvolvimento infantil; na Idade Média, seu valor na sociedade se dava a partir dos sete anos - idade da razão - quando a criança aprendia a se comunicar oralmente, podendo, então, trabalhar e partilhar da vida dos adultos. Antes de chegar a essa idade, as crianças das classes não abastadas, buscavam so- 
breviver em meio à violência, promiscuidade, falta de hábitos de higiene, entre outros aspectos desse período histórico, ou seja, não havia uma ideia de proteção. Na Idade Moderna, mais precisamente no século $\mathrm{XV}$, surge a prensa tipográfica e, com ela, a necessidade de pensar na infância, como afirma Postman:

[...] quando a prensa tipográfica fez sua jogada, tornou-se evidente que uma nova espécie de idade adulta tinha sido inventada. A partir daí a idade adulta tinha de ser conquistada. Tornou-se uma realização simbólica e não biológica. Depois da prensa tipográfica, os jovens teriam de se tornar adultos e, para isso, teriam de aprender a ler, entrar no mundo da tipografia. E para realizar isso precisariam de educação. Portanto a civilização europeia reinventou as escolas. E ao fazê-lo, transformou a infância numa necessidade. (POSTMAN, 1999, p. 50).

O pensamento em relação à infância, como podemos perceber, em geral partia do olhar do adulto sobre a criança, configurando-a, por vezes, em uma versão "miniaturizada" dessa geração ou, então, a partir da ideia de incompletude e imperfeição desse ser em relação àquele. Do período Clássico à Idade Moderna, portanto, observa-se que a criança se tornou submissa às construções adultas sobre sua geração, mas e hoje, na contemporaneidade, qual é o pensamento que se constrói socialmente em relação à infância?

Pode-se encontrar nos estudos referentes à Sociologia da Infância um caminho para obter tais respostas. Apesar da criança não ser um tema ausente no pensamento sociológico e na construção de suas bases de pesquisa, é recente seu protagonismo, ou seja, seu reconhecimento como sujeito/ator social. Como afirma Jens Qvortrup (1999) “[...] com um atraso de quase um século, em comparação a psicólogos, psiquiatras, pedagogos etc., os sociólogos da infância reuniram-se pela primeira vez em 1900, no Congresso Mundial de Sociologia" (apud DEMARTINI, 2009, p. 10). Foi a partir dessa década, que se observou um aumento significativo de pesquisas em muitos países e que a Sociologia da Infância definiu o lugar das crianças nos estudos da área.

Anteriormente, as crianças ocupavam um pequeno espaço 
dentro das pesquisas desenvolvidas nessa área, principalmente, dentro da Sociologia da Família e da Educação. As tradicionais teorias de socialização, tendo como principal representante o sociólogo Émile Durkheim (1858-1917), contribuíram para a invisibilização da infância ao considerar as crianças "[...] como um simples objeto passivo de uma socialização regida por instituições." (SIROTA, 2001, p. 09). Segundo a socióloga da infância Régine Sirota, por um longo período de tempo, sociólogos dedicaram suas pesquisas para as instâncias e instituições encarregadas pelo trabalho de socialização, desenvolvendo diferentes olhares cujo foco era a criança em relação às instituições e não sobre ela como sujeito em si.

Em relação a teoria de socialização de Durkheim e a visão da criança como passiva nesses processos, Sirota complementa:

A criança é, pois, aqui considerada antes de tudo como aquilo que os anglo-saxões denominam um "future being", um ser futuro, em devir: 'ela [a infância] apresenta ao educador não um ser formado, não uma obra realizada e um produto acabado, mas um devir, um começo de ser, uma pessoa em vias de formação. Não importa que período da infância consideremos, sempre nos encontramos em presença de uma inteligência tão fraca, tão frágil, tão recentemente formada, de constituição tão delicada, com faculdades tão limitadas e exercendo-se por um tal milagre que, quando pensamos nisso tudo, não há como não se temer por essa esplêndida e frágil máquina'. (SIROTA, 2001, p. 09).

É, principalmente, em oposição à essa concepção de infância, que vão surgir e se fixar os primeiros elementos de uma Sociologia da Infância. Ao considerar as crianças como atores sociais e como sujeitos de direitos, a sociologia assumiu suas participações como protagonistas nos processos de investigação social, delineando-as como questão central na definição de um estatuto social da infância e na caracterização do seu campo científico: “[...] Considerar a participação das crianças na investigação é um passo decorrente da construção de uma disciplina das ciências sociais que procura 'ouvir a voz das crianças' [...]" (SARMENTO; SOARES; TOMÁS, 2005, p. 66). Reconhecê-las como seres sociais plenos, com interpretações próprias sobre seus mundos de vida, 
a partir das quais, podem revelar, para além delas, as realidades dos contextos sociais onde se inserem e suas opiniões acerca dos mais variados assuntos, é o que move essa área de pesquisa.

Ao afirmar que a criança é um ser social, a Sociologia da Infância propõe retirá-la da passividade frente às concepções de mundo do adulto, para reconhecê-la como sujeito capaz de comunicar suas próprias percepções. Esse pensamento parte da observação da diferença entre essas duas gerações (crianças e adultos) e não da incompletude de uma frente à outra. A criança é um ser humano capaz de comunicar verbalmente, corporalmente, artisticamente, suas opiniões sobre qualquer assunto, tornando singular sua maneira de se expressar, não se igualando a nenhuma outra faixa etária.

Nesse sentido, a postura de quem se dedica à pesquisa com grupos infantis necessita se assemelhar à proposta pelo sociólogo da infância Claude Javeau:

O antropólogo das crianças não somente deve esforçar-se para reencontrar uma 'alma de criança' mas deve também adquirir uma alma de historiador, dobrada, se for o caso, de uma alma de jurista e de uma de economista. Como se vê, praticar a 'sociologia da infância', como qualquer outra aliás, exige das equipes de especialistas que se dedicam a esse campo, ainda em plena elaboração, um leque de competências extremamente variadas. (JAVEAU, 2005, p. 388).

Como observa o autor, a pessoa que se dedica a pôr em prática a Sociologia da Infância deve, antes de tudo, reconectar-se a sua infância, à sua criança adormecida, e a partir dela, traçar as relações necessárias para contribuir para que tantas outras crianças possam viver, falar e expressar suas infâncias. Nesse sentido, a Sociologia da Infância contribuiu para a construção de um pensamento sobre as infâncias contemporâneas e seus contextos de vida, reafirmando a necessidade de repensar a infância a partir de sua pluralidade, colaborando para além da teoria, para a construção de uma postura ética de trabalho frente às crianças. 


\section{NOS CAMINHOS DA COMUNIDADE}

O teatro na comunidade é uma prática que pode se manifestar de diversas formas. Está presente nas propostas teatrais de vários países assumindo diferentes nomes em determinados lugares: "[...] teatro popular, teatro para o desenvolvimento, teatro radical do povo, teatro para a libertação, etc.," (NOGUEIRA, 2009, p. 173). Trata-se de uma modalidade teatral difícil de definir, uma vez que adquire diferentes formatos, ligada a diferentes instituições e finalidades. Na tentativa de buscar uma definição, aproximei-me dos estudos da pesquisadora e professora Marcia Pompeo Nogueira (2009), referência no nosso país ao pesquisar as relações entre Teatro e Comunidade no contexto brasileiro.

A definição do que seria teatro na comunidade que propõe a autora, muito influenciada pelo trabalho de Baz Kershaw, traz uma ideia interessante, partindo da relação da produção teatral com as questões de interesse da própria comunidade:

Sempre que o ponto de partida [de uma prática teatral] for a natureza de seu público e sua comunidade. Que a estética de suas performances for talhada pela cultura da comunidade de sua audiência. Neste sentido estas práticas podem ser categorizadas enquanto Teatro na Comunidade. (KERSHAW apud NOGUEIRA, 2009, p. 173).

O que os autores propõem, vai além de uma definição do que seria o teatro na comunidade. Diz respeito ao comprometimento de observar esse lugar, pensar e repensar uma prática teatral a partir dele e com as pessoas que dele fazem parte. É reconhecer que de cada lugar emanam questões incomparáveis que precisam dialogar com as práticas teatrais propostas. Embora seja vasto o leque de termos, definições e modos de fazer envolvendo o teatro na comunidade, tudo indica que essas práticas possuem aspectos bastante comuns, como salienta Nogueira:

Trata-se de um teatro criado coletivamente, através da colaboração entre artistas e comunidades específicas. Os processos 
criativos têm sua origem e seu destino voltados para realidades vividas em comunidades de local ou de interesse. De um modo geral, mesmo usando terminologias diferentes, esboça-se um método baseado em histórias pessoais e locais, desenvolvidas a partir de improvisação. Cada terminologia, a seu modo, guarda relações com um processo educativo entendido ou não como transformador. Do meu ponto de vista podemos, no Brasil, chamar essas práticas de Teatro em Comunidades. (POMPEO apud COUTINHO, 2010, p. 87).

Assim como outras modalidades de teatro, o Teatro na Comunidade apresenta alguns modelos de trabalho. Nogueira $(2009,2008)$ aponta três modelos: teatro para, com e pela comunidade. A autora ainda salienta, que os modelos sofreram transformações partindo de práticas hierárquicas realizadas de cima para baixo, para práticas cujos objetivos e métodos são decididos pelas pessoas que participam dos projetos teatrais. O que existe em comum entre eles é que "[...] são representados fora dos holofotes metropolitanos" (ERVEN apud NOGUEIRA, 2009, p. 177), propondo a descentralização da arte, reconhecendo e valorizando as manifestações artísticas que emergem das zonas periféricas e esquecidas das cidades.

Para além do envolvimento da comunidade como sujeita no processo criativo, algumas experiências de teatro pela comunidade estão redirecionando o foco de suas práticas. A pesquisadora brasileira Marina Henriques Coutinho, em sua tese de doutorado, aponta que emergem diariamente, em vários lugares do mundo, exemplos de trabalhos teatrais desenvolvidos pela comunidade que estão apostando:

[...] menos na 'discussão de problemas' e mais na ideia de que o fazer teatral pode representar, em si, a afirmação da voz e do corpo das comunidades, explorando o espaço teatral como um lugar onde podem se manifestar as suas formas artísticas, os valores da cultura local, o seu protagonismo. (COUTINHO, 2010, p. 135). 
Práticas teatrais com esse objetivo favorecem o surgimento de culturas, muitas vezes vistas como periféricas e marginais, contribuindo para o reconhecimento e a valorização dessas manifestações artísticas como representações autênticas que emergem de cada lugar. Nesse sentido, os objetivos e questões da pesquisa desenvolvida foram ao encontro do teatro pela comunidade, encontrando um lugar no qual as crianças, muitas vezes silenciadas e silenciosas dentro de seus contextos de vida, pudessem se expressar a partir da linguagem teatral, revelando suas opiniões acerca dos mais variados assuntos e, principalmente, sobre aqueles que não são consideradas "capazes" de compreender.

\section{ASSOCIAÇÃO ESPERANÇA}

A Associação Esperança se localiza na Cohab Fernando Ferrari, no bairro Camobi, na cidade de Santa Maria/RS. Em algumas conversas com a dona Vera, presidente da associação, fui descobrindo um pouco da história desse espaço comunitário, fundado em 2008 por moradores do local. Com o objetivo de criar um espaço de convívio que comportasse a realização de atividades culturais, distribuição de alimentos, entre outras atividades destinadas, principalmente, à população carente local, a sede da associação foi construída pelos próprios moradores na ocasião de sua fundação. Hoje, após passar por algumas reformas, conta com um espaço abrangente, com cozinha, banheiro e um grande pátio ao redor.

Em relação à gestão desse espaço, foi eleita uma diretoria formada por moradores, mas que não funciona na prática, visto que muitos integrantes não residem mais na cohab. A moradora Vera ${ }^{1}$ é a única representante dessa diretoria que ainda permanece atuando na associação, configurando-se como o pilar central dessa comunidade, uma vez que, em torno dela, e a partir dela, todas as decisões são tomadas.

Atualmente, a associação concentra suas atividades na distribuição de alimentos para aproximadamente 20 famílias, pre-

1 As informações sobre a comunidade foram coletadas a partir das memórias de Dona Vera a mim relatadas. 
viamente cadastradas e contribuintes com um valor simbólico para que a associação possa se manter em funcionamento. Os alimentos remanescentes do Restaurante Universitário da UFSM são doados pela universidade, coletados por Vera e um outro morador, e distribuídos às famílias nas quartas e sextas-feiras. As famílias que recebem os alimentos, em geral, são numerosas, com quatro, cinco, seis filhos. Todas residem na comunidade, mas já houve casos de famílias que se deslocavam de outros bairros para participar da distribuição.

Quando conversei com dona Vera sobre a possibilidade de realizar as oficinas com as crianças, ela prontamente disse que 0 espaço estava aberto para me receber. Retornei, no dia seguinte, para acompanhar a distribuição de alimentos que, na ocasião, aconteceu em uma quarta-feira à noite. Conheci algumas famílias, expliquei sobre o projeto das oficinas de teatro, e perguntei se poderiam me auxiliar na divulgação, convidando as crianças membros de suas famílias, bem como, outras que moravam próximas.

Como moradora da Cohab Fernando Ferrari, gostaria de contribuir para a revitalização da Associação Esperança, que somente pode ser erguida através da força do seu povo e que deve ser mantida, alimentada, reconstruída pela força, luta e organização popular. É nesse contexto de luta pela sobrevivência desse espaço, que eu e as crianças nos encontramos semanalmente. Acredito que enquanto houver pessoas trabalhando e lutando pela associação, as portas sempre estarão abertas e a possibilidade de que outros se agreguem para contribuir pode vir a aumentar.

\section{UM VENTOFORTE SOPROU SOBRE A INFÂNCIA}

Fundado em 1974 por llo Krugli, na companhia de Silvia Aderne, Caique Botkay, Silvia Heller, Beto Coimbra e Alice Reis, o Teatro Ventoforte completou, em 2018, 44 anos de existência e intensa produção artística e cultural. O diretor, figura central no grupo, que também é ator, escritor, arte-educador, artesão, bonequeiro, dramaturgo, cenógrafo, figurinista, compositor, carpinteiro, iluminador, artista plástico e bordadeiro, nasceu no ano de 
1930, em Buenos Aires, Argentina, em uma família de operários imigrantes poloneses.

Em 1961, Krugli chegou ao Brasil a convite do artista plástico Augusto Rodrigues, integrando o movimento das Escolinhas de Arte do Brasil (EAB), na cidade do Rio de Janeiro. Seu ponto de partida para o trabalho foi a livre expressão, um trabalho contínuo de criação a partir da improvisação, buscando desenvolver a sensibilidade e o autoconhecimento dos participantes das oficinas ministradas por ele. Percebe-se como fundamental na formação de Krugli o trabalho realizado na Escolinha de Arte que, posteriormente, influenciou suas práticas no Ventoforte.

Em meio às circunstâncias políticas e à trajetória pessoal de Krugli, o Ventoforte surgiu como um teatro de resistência. Suas peças falavam das realidades mais cruéis e agitavam sempre a bandeira da liberdade, mas sem panfletismo; e, sim, como metáfora poética. A aventura que llo Krugli e o Teatro Ventoforte compartilham com o público é, principalmente, estética. Foi a sua força poética transportada para o palco que o conduziu a criar um jeito de conversar com crianças e adultos, circulando com naturalidade entre as duas gerações, tornando-se referência para artistas e educadores.

Música, dança, invenções e poesias compõem as histórias levadas à cena pelo Ventoforte, encantando pessoas de todas as idades. Em meio a retalhos, sucatas, bordados, bonecos, atores e público, o teatro vai acontecendo, juntamente com o espírito festivo que caracteriza as apresentações do grupo. Segundo Abreu:

Cada peça é uma aventura que envolve, diverte e faz pensar. Como poucos, llo realiza a magia do teatro de animação, seres inanimados criam alma e vida, sejam bonecos sofisticados no palco e na platéia, ou simples objetos como uma folha de papel à mercê dos ventos ou da mão pesada do homem. (ABREU, 2009, p. 24).

Teatro, para o Ventoforte, significa uma forma de conhecimento, de revelação de enigmas. Todo material de cena é criado artesanalmente por Krugli e o grupo, sendo uma característica marcante nos seus trabalhos, tornando o fazer artesanal elemen- 
to básico da linguagem teatral. O trabalho com as mãos é fundamental na prática do grupo, pois é através delas que se criam formas que trazem, por trás, os seus significados. As imagens internas dos participantes ganham materialidade nos desenhos, nos bonecos e se desenvolvem gerando histórias. As histórias podem ser de verdade ou de mentira, sendo que nas duas alternativas se revelam as percepções de mundo dos participantes.

Krugli e o grupo vão para as comunidades periféricas e carentes de tudo e lá fazem a festa, na tentativa de eliminar a distância entre quem faz e quem vê teatro. Assim, o público participa ativamente do espetáculo, apresentado em pátios, praças e ruas. Marcia Pompeo Nogueira (2008) percebe a aproximação de Krugli e do Ventoforte com a comunidade, quando nas décadas de 1980 e 1990, acompanha o trabalho desenvolvido pelo grupo, em projetos ${ }^{2}$ realizados na cidade de São Paulo.

Pode-se observar, a partir dos escritos de Nogueira (2008), sobre os trabalhos que acompanhou e participou junto às comunidades em São Paulo, que se trata de uma proposta de teatro por/pela comunidade que têm por objetivo desvendá-la, bem como, desvendar, também, suas histórias, seus lugares, sua gente. Tudo isso se mistura às histórias de vida dos moradores: crianças, jovens e velhos, e se cria um espaço em que todos podem participar juntos, contribuindo para a construção do lugar onde se vive, e de uma identidade comunitária pertencente a todos que partilham desse espaço.

Ao longo de 44 anos de trabalho, Krugli comprometeu-se com o ser criança, que sempre o instigou, delineando os caminhos de suas práticas. "Ele identifica a criança como raiz arcaica do homem, menos influenciada pelos padrões sociais, mais aberta, mais espontânea, portanto, especialmente dotada para a sua proposta estética." (NOGUEIRA, 2008, p.92). A partir das observações de Nogueira (2008), pode-se compreender um pouco mais o pensamento do diretor em relação à criança:

2 Projeto Enturmando (1988) e Projeto A Turma Faz Arte (1989), ambos da Secretaria do Menor, da cidade de São Paulo; Casa de Cultura Mutirão São Franscisco (1990), vinculado a Secretária Municipal de Cultura de São Paulo. 
A criança é considerada uma fonte de pesquisa, um ser especialmente dotado para a captação das imagens do inconsciente. [...] A pesquisa de llo envolve a criança da criança, a criança do jovem, a do adulto e a do velho. Ao trabalhar com todas as idades, busca-se as imagens, as lembranças da infância. (NOGUElRA, 2008, p. 92).

A aproximação de Krugli com o ser criança foi o que despertou meu interesse pelo seu trabalho e pelas práticas que desenvolveu no Ventoforte. Percebo uma aproximação com o que propõe a Sociologia da Infância, ao afirmar que a criança precisa ser considerada como um ser social capaz de se expressar, comunicar suas percepções de mundo e parece-me que o teatro pode ser essa linguagem; uma possibilidade de deixar fluir as imagens da infância de cada criança.

\section{CONSTRUINDO UMA ABORDAGEM METODOLÓGICA PARA O ENSINO DO TEATRO COM CRIANÇAS NA COMUNIDADE}

Passeando pelos caminhos de Ilo Krugli e do Teatro Ventoforte, descobriu-se alguns "pontos de referência" que poderiam orientar a construção de um outro caminho: o meu. Em busca de uma abordagem metodológica para o trabalho com crianças na comunidade, deparei-me com algumas práticas teatrais, percebendo que poderia me aventurar em um caminho desconhecido, porém, intrigante. Pode-se observar que as práticas do Ventoforte abrem espaço para a presença das crianças, as quais foram parceiras na pesquisa. A partir de quatro propostas metodológicas destacadas por Nogueira (2008), que as práticas pedagógico-teatrais desenvolvidas com as crianças da Associação Esperança foram estruturadas.

Uma prática teatral central no trabalho de llo Krugli e do Teatro Ventoforte é chamada de caminhos. Trabalhar com o tema caminhos significa observar o movimento, caminhar, passar pelas coisas, ir de um lugar a outro. O objetivo é a sensibilização a partir 
dos caminhos do cotidiano: o que existe nesse caminho? A proposta é que cada criança percorra um caminho realizado, de olhos fechados, prestando atenção aos sons, cheiros, cores e silêncios que surgem nesse trajeto, e que muitas vezes, passam despercebidos. O caminho pode ser até o lugar onde nos encontramos, ou então, o caminho de casa até a escola, entre outros caminhos percorridos pelas crianças.

Após esse momento de sensibilização, os caminhos de cada criança são registrados a partir de desenhos em papel, individualmente. A proposta segue para os desenhos com giz no chão, nos quais tudo deve ser representado: as pessoas do caminho de cada um, os sons, o clima, os cheiros, os caminhos que se cruzam, enfim, tudo que foi observado por cada criança no momento anterior, pode ser representado em seu desenho. Os caminhos das crianças se cruzam com os caminhos da comunidade e dos outros moradores, e aos poucos, a comunidade vai aparecendo e tomando forma através do olhar das crianças.

Outra prática desenvolvida chama-se histórias de verdade e de mentira. Podem ser as histórias que acontecem nos caminhos explorados da comunidade, bem como, histórias que envolvem moradores, ou situações vividas naquele lugar. Percebe-se que há uma relação direta com a prática dos caminhos, unindo-se aspectos reais e imaginários dos contextos sociais nos quais vivem as crianças. $\mathrm{O}$ desenho também aparece nessa prática e possibilita visualizar essas histórias. Também pode ser proposta a escrita da história de cada criança ou a criação de uma grande história coletiva.

Para Nogueira, "Deslocar o sentido da história para incluir a fantasia permite um novo olhar para o real, livre de culpa, de medo de se expressar. Na 'mentira', histórias profundas podem ser reveladas e elaboradas mais facilmente e se ganha licença poética para brincar com elas" (2015, p. 17). Assim, não importa identificar o que é real e o que é ficcional, mas sim, garantir que cada criança possa se sentir livre e segura para criar e compartilhar suas histórias.

Os mapas da vida, uma das práticas mais conhecidas dentre as que são desenvolvidas por Krugli e o Ventoforte, propõe aos participantes a construção de bonecos a partir de sucatas, panos, objetos e demais materiais. A partir disso, são convidados a criar 
um mapa da vida desse ser, que surgiu pelas suas mãos. Em geral, são propostos três mapas: o primeiro representa o personagem antes de nascer; o segundo representa o presente; e, por fim, um terceiro com as projeções para o futuro do personagem. Para Nogueira (2008), o trabalho com os mapas da vida explora espaços diversos da memória, do imaginário, dos sonhos e desejos de cada criança.

O desenho também está presente nesta prática. Pode-se imaginar um personagem e desenhá-lo, para somente depois confeccioná-lo. O passado, o presente e o futuro do personagem também podem ser desenhados no papel. Em algum momento, todos podem apresentar seus personagens, criar um nome, profissão, características, entre outras informações. O mapa da vida desenhado no papel pode gerar improvisações com os personagens/bonecos, e a história de sua vida pode ser apresentada pelas crianças.

A quarta prática teatral elencada chama-se fotografando a comunidade. A partir de uma máquina fotográfica, confeccionada por cada criança, com materiais alternativos, é proposto que todos saiam pela comunidade "fotografando-a", fixando imagens a partir de um pequeno furo ou enquadramento, observando detalhes que muitas vezes não se percebe no cotidiano.

O objetivo dessa prática é "revelar" as fotografias da comunidade que cada criança tirou a partir da criação de desenhos. Neles, podem-se revelar as percepções das crianças a acerca da comunidade, bem como, expandir seu olhar sobre os espaços pouco observados no cotidiano, e que compõem o lugar onde vivem. Pode-se juntar a essa experimentação a prática dos caminhos, de maneira que, cada criança com a sua máquina fotográfica possa refazer seu caminho e perceber os detalhes que anteriormente lhe passaram despercebidos.

Além de fotografar os caminhos, pode-se explorar outros lugares da comunidade que sejam de interesse das crianças, como por exemplo, uma casa abandonada, uma praça ou uma paisagem. Nogueira (2008) relata que em uma prática de fotografar a comunidade que acompanhou, Krugli sugeriu que as crianças fotografassem procurando cores. Enfim, tudo pode ser fotografado: desde paisagens a pequenos detalhes. 


\section{AS CRIANÇAS E SUAS CRIAÇÕES}

A partir das práticas teatrais desenvolvidas pelo Teatro Ventoforte, apresentadas anteriormente, organizou-se os planejamentos dos encontros com as crianças. Realizaram-se sete encontros, que aconteceram semanalmente na sede da Associação Esperança, localizada na cidade de Santa Maria/RS. A participação das crianças nos encontros se construiu de maneira livre e autônoma, o que resultou em um público flutuante. No entanto, quatro meninos, com faixa etária entre sete e onze anos, participaram de todos os encontros.

Os planejamentos também foram construídos semanalmente considerando as experiências e vivências do grupo em cada encontro. Ademais, priorizou-se que os planejamentos possibilitassem a continuidade dessas experiências, de modo a enfatizar um processo criativo em construção, tendo o cuidado para não recair em práticas isoladas e fragmentadas.

Desse modo, a estrutura geral dos encontros era organizada em quatro momentos. O momento inicial era dedicado para brincadeiras e jogos teatrais que priorizassem a integração das crianças, de maneira que, todas se mobilizassem em prol da realização de uma atividade coletiva. Esse momento se caracterizava pela diversão que esses jogos proporcionavam e pelo engajamento das crianças nas propostas. Mais do que meras sugestões, as crianças direcionavam as brincadeiras e jogos, criando, a todo momento, novas formas de experimentá-las.

Em um segundo momento eram experimentadas as práticas do Teatro Ventoforte. Essas práticas não possuíam um planejamento fechado, pelo contrário, apresentavam uma espécie de roteiro, com orientações e objetivos específicos, porém, seu desenvolvimento se dava de maneira livre, na qual, os processos de experimentação dessas práticas eram conduzidos pelas crianças, a partir de suas criações. Cabe ressaltar que as possibilidades que essas práticas suscitam são inúmeras, e que nesse caso, criou-se uma maneira única de experimentá-las com as crianças nesse contexto educacional. Essa é uma característica que podemos encontrar em todas as práticas do Ventoforte, nas 
quais, não há uma receita a seguir, um caminho, mas sim, inúmeros caminhos.

Após a experimentação dessas práticas teatrais os encontros se encaminhavam para um terceiro momento, no qual, as crianças eram convidadas a criar diversas materialidades a partir de desenhos, histórias, improvisações e confecção de bonecos. Esse momento do encontro sempre foi recebido pelas crianças com grande entusiasmo. Os materiais necessários para a concretização dessas materialidades eram disponibilizados por nós, porém, cada criança poderia utilizá-los da maneira que quisesse.

Para finalizar nossos encontros, sempre era proposto um último momento, no qual, conversávamos sobre o que havíamos feito naquela tarde. As crianças contribuíam com suas impressões sobre as experimentações realizadas, bem como, com sugestões para os próximos encontros.

Para responder a questão da pesquisa, o que criam as crianças?, foi resgatado no último capítulo desse trabalho de conclusão de curso, os planejamentos de todos os encontros, as materialidades criadas com/pelas crianças e a avaliação posterior aos encontros. Percebeu-se que as materialidades criadas e expostas a partir de fotos já respondiam essa questão e, portanto, afastei-me de qualquer análise psicológica e interpretativa sobre esse material. $\mathrm{O}$ foco recaiu sobre a apresentação desses materiais e contextualização ao leitor sobre o momento em que foram criados.

\section{CONSIDERAÇÕES FINAIS}

Ao longo da escrita deste trabalho, procurei respostas aos questionamentos que surgiam e preenchiam minha cabeça. Em relação ao teatro na comunidade, questionei-me sobre a prática que estava desenvolvendo dia após dia. O que pulsava em mim era o desejo de revelar aquela comunidade a partir do olhar das crianças, mas para isso, precisava conhecê-la. Então, acompanhei algumas atividades desenvolvidas pela Associação Esperança, o que revelou a necessidade de pensar uma prática verdadeiramente preocupada com aquele lugar. Pensando que tudo tem história: as paredes, os quadros com fotos, as panelas, os peda- 
ços de paus, as cadeirinhas, as pessoas... Tudo. Enfim, me questionava sobre minha postura ética frente a este trabalho, e como não anular essas histórias, as histórias dessa comunidade.

A Sociologia da Infância contribui com alguns questionamentos que me possibilitaram (re)pensar as crianças e suas infâncias. Em minhas leituras acerca desse assunto, sempre se destacava a frase: dar voz às crianças. Questionei-me: "como? O que fazer quando essa voz falar? Como escutá-la?". Sempre que me colocava frente às crianças essa frase pulsava em mim. As crianças tinham muito a dizer, sempre. E, pensando que o corpo também fala, assim como os gestos, o contato com o outro, as roupas, tudo comunica, percebi que o meu lugar deveria ser o de escuta. Ouvir as crianças requer a habilidade de estar atenta, uma vez que, muitas vezes silenciadas, quando elas têm a possibilidade de falar, e a companhia de alguém para escutá-las, falam sobre tudo, revelando a complexidade de ser criança nessa sociedade contemporânea.

O Teatro Ventoforte foi por muito tempo como uma miragem, que eu via de longe, distante, quase inalcançável. Por não ter tido nenhum contato com esse trabalho antes desta pesquisa, pensava que não poderia conduzir um processo, pois, me faltava o conhecimento do corpo, da vivência, da prática. Porém, mesmo com tantas incertezas, aventurei-me por esse caminho. Hoje, percebo a genialidade da obra de llo Krugli e do que ela representa tanto para o teatro com crianças, quanto para o teatro com a comunidade, e vislumbro que muitos caminhos ainda podem ser percorridos por mim na direção desse Ventoforte.

A questão que me intrigou e me mobilizou a escrever este trabalho, diz respeito às crianças e suas criações. O que elas criam? Enquanto me perguntava isso, planejava os encontros com as crianças. Posteriormente, tentava organizar as materialidades criadas nesses encontros e, que poderiam responder essa questão. Comecei a me questionar sobre como apresentaria esse material nessa pesquisa e o que gostaria de falar sobre ele. Percebi que teria que me afastar de qualquer análise psicológica, ou algo do gênero. Falar sobre o que as crianças criam é diferente de pensar porque as crianças criam. Essa questão deixo para outras áreas de pesquisa responderem. 
Em meu trabalho de conclusão de curso, apresentei as crianças da cohab e suas criações a partir de desenhos, imagens, bonecos, relatos e histórias. E onde está o teatro no meio disso tudo? Certa vez, questionaram-me sobre "o que de teatro tem nesse trabalho?". Percebi, que do "velho" teatrinho para criancinhas, que "ensina" como fazer tal coisa, ou mostra como o bem sempre vence o mal, não existia nada mesmo. Não temos falas decoradas nem marcações pelo espaço. Ninguém é obrigado a fazer nada que não queira. Criamos um espaço para experimentar o teatro, compartilhar vivências, brincar. Imaginar outro mundo possível, menos desigual e que respeite a todos os seres humanos, principalmente, os de pouca idade. 


\section{REFERÊNCIAS}

ABREU, leda de. Ilo Krugli: Poesia Rasgada. São Paulo: Impressão Oficial, 2009.

COUTINHO, Marina Henriques. A favela como palco e personagem e o desafio da comunidade-sujeito. 2010. Tese (Doutorado em Artes Cênicas) - Centro de Letras e Artes, Universidade Federal do Estado do Rio de Janeiro, Rio de Janeiro.

DEMARTINI, Zeila de Brito Fabri. Infância, pesquisa e relatos orais. In: FARIA, A. L. G., DEMARTINI, Z. B. F., PRADO, P. D. (Org.) Por uma cultura da infância: metodologias de pesquisa com crianças. Campinas: Autores Associados, 2009, p. 1-17.

JAVEAU, Claude. Criança, infância(s), crianças: que objetivo dar a uma ciência social da infância? Revista Educação \& Sociedade. Campinas, n. 91, 2005. p. 379-389.

NOGUEIRA, Marcia Pompeo. Ventoforte: no teatro em comunidades. Florianópolis: Letras Contemporâneas, 2015.

. Teatro e Comunidade. In: FLORENTINO,

A., TELLES, N. (Org.) Cartografias do Ensino do Teatro. Uberlândia: EDUFU, 2009. p. 173-183.

- Teatro com meninos e meninas de rua: nos caminhos do grupo Ventoforte. São Paulo: Perspectiva, 2008.

A opção pelo Teatro em Comunidades:

Alternativas de pesquisa. Revista Urdimento. Florianópolis, n. 10, 2008. p. 127-136.

SARMENTO, Manuel Jacinto. A reinvenção do ofício de criança e de aluno. Revista Atos de Pesquisa em Educação. Blumenau, n. 3, 2011. p. 581-602.

- Sociologia da Infância: Correntes e 
Confluências. In: SARMENTO, M. J., GOUVÊA, M. C. S. (Org). Estudos da Infância: educação e práticas sociais. Petrópolis: Vozes, 2008.

SARMENTO, M. J., SOARES, N. F., TOMÁS, C. A. Investigação da infância e crianças como investigadoras: metodologias participativas dos mundos sociais das crianças. Revista Nuances. Presidente Prudente, n. 13, 2005. p. 50-64

SIROTA, Régine. Emergência de uma Sociologia da Infância: evolução do objeto e do olhar. Revista Cadernos de Pesquisa. São Paulo, n. 112, 2001. p. 7-31

POSTMAN, Neil. O Desaparecimento da Infância. Rio de Janeiro: Graphia, 1999.

VIEIRA, Miguel Vellinho. Ilo Krugli e a construção de um novo espaço poético para o teatro infantil no Brasil. 2008. Dissertação (Mestrado em Artes Cênicas) - Centro de Letras e Artes, Universidade Federal do Estado do Rio de Janeiro, Rio de Janeiro. 